\title{
O Diagnóstico das Demências
}

\author{
Dr. Ceme Ferreira Jordy*
}

\section{AESUMO}

O seguinte artigo apresenta um breve histórico da evoluçăo conceitual do Autismo Infantil, desde sua primeira descriçăo em 1943 por Leo Kanner até os dias atuais. Analisa também as novas tendências no que se refere aos critérios diagnósticos e classifjcacóes da Síndrome Atlstica na CID 10 e DSM IV.

\section{UNITERMOS}

Conceito, Diagnóstico, Fisiopatogênia, Eliologia.
A abordagem deste assunto impōe, de início, a consideração de três etapas de trabalho a realizar:

1) O diagnóstico clínico de demência;

2) O diagnóstico fisiopatogênico da demência;

3) O diagnóstico etiológico da demência. Vejamos então, como realizar, por ordem, tais etapas de diagnóstico.

\section{O DIAGNÓSTICO CLINICO DE DEMENCIA}

Tem sido muito generalizada em centros especializados, em quase todos os países, a aceitação dos critérios clínicos para o diagnóstico de demência, recomendados pela Associação Americana de Psiquiatria. Não resta dúvida para considerar que tal aceitação reside no fato de ser o DSM, resultado de cuidadosa pesquisa, que o faz representar, em suas linhas gerais, um sumário do consenso mundial sobre o assunto. Especifique-mo-lo:

1) Comprometimento da capacidade de fixação de vivências atuais e da capacidade de evocação de vivências do passado próximo ou remoto.

2) Presença de um dos seguintes itens:

a) Comprometimento do pensamento abstrato;

b) Comprometimento do juízo;

c) Presença de afasia, agnosia, apraxia, transtomo da capacidade construtiva;

d) Mudança de personalidade em termos qualitativos ou quantitativos. Como decorrência dos itens A) e B), o aparecimento de transtornos no desempenho social. Estas alterações não serão consideradas quando ocorrerem no curso de Delirium. No DSM acrescentam-se aos critérios clínicos de diagnóstico, a existência de fator orgânico e a exclusão de distúrbio mental grave como a Depressão Maior, capaz de comprometer funções cognitivas.

$\mathrm{Na}$ Unidade de Atendimento a Transtornos da Memória e Demências do Ambulatório de Neurologia da Escola Paulista de Medicina, utilizamos as recomendaçōes do NINCDS-ADRDA, (National Institute of Neurological and Communicative Disorders and Stroke-Alzheimer's Disease and Related Disorders Association), que reune as conclusões de um grupo de trabalho que pesquisou critérios de inclusão e critérios de exclusão para o diagnóstico presumptivo da doença de Alzheimer. Reune medidas anamnésticas, clínicas e laboratoriais bioquímicas, neurofisiologicas e neuroradiológicas. Incluímos na fase clínica desta pesquisa diagnóstica a utilização de tabelas e de testes neuropsicologicos destinados a aferir funçōes cognitivas e, também, testes projetivos que se
Prof. Adjunto e Livre-Docente da Disciplina de Neurologia do Departamento de Neurologia e Neurocirurgla da Escola Paulista de Medicina. 
destinam a avaliar os aspectos afetivos da personalidade. Assim concluímos a primeira etapa da pesquisa diagnóstica. Estabelecido o diagnóstico clínico de demência, poderemos passar a avaliar os seus mecanismos patogênicos.

\section{O DIAGNÓSTICO FISIOPATOGENICO DA DEMENCIA}

A característica clínica mais marcante da demência é a perda cognitiva. Na quase totalidade dos pacientes o primeiro sintoma-sinal é uma perda insidiosa da memória, que pode se expressar por qualquer de suas formas clínicas embora, mais frequientemente, por dificuldade em evocar nomes, em "encontrar a palavra certa". As evidências laboratoriais mais constantes na literatura atual, relacionam a perda de memória, direta e proporcionalmente à perda neuronal nas formaçöes hipocampais. Há outras estruturas neuronais especialmente hipotalâmicas, talâmicas e septais, implicadas no processo manemônico, em suas diversas fases ou modalidades. Pois aquelas e estas estão, entre as localizações anatômicas, que têm sido descritas nos estádios iniciais das degeneraçōes neuronais, que se acompanham de demência. A degeneração do núcleo de Meynert compromete a maior fonte de inervação colinérgica para a córtex cerebral e prosencéfalo e a degeneração do Locus Coeruleus compromete a talvez mais importante origem de inervação adrenérgica ascendente. Redução no número absoluto de receptores para diferentes agentes neurotransmissores, tem sido revelada por pesquisas realizadas nos últimos anos. Estes dados, obtidos por diferentes investigadores, são relatados com frequência crescente na literatura dos últimos 6 ou 7 anos e revelam alterações em quase todas as regiōes da cortex cerebral e cerebelar e em numerosos locais dos núcleos sub-corticais, incluindo os do tronco cerebral e da medula espinhal. Estes estudos, realizados in vivo e em extenso material post-mortem, são uma demonstração segura das lesões a que fica sujeito o Sistema Nervoso em quase todas as suas estruturas encefálicas, especialmente telencefálicas, na doença de Alzheimer e em outras formas de degeneração primária do parênquima encefálico. Assim, amplamente lesado, o Sistema Nervoso falha no desempenho de numerosas funções, especialmente funções cognitivas, principal característica da síndrome demencial.

Cabe notar que nesta última década, por iniciativa de alguns neurologistas norte-americanos, passou-se a designar, em segmentos do âmbito científico, dois tipos de demência:

- cortical;

- sub-cortical.

O primeiro, tendo como exemplo típico, o da doença de Alzheimer e o segundo, o da doença de Parkinson. No primeiro tipo, as lesões predominam na cortex cerebral, dizem esses neurologistas e, no segundo, em regiōes sub-corticais. Ora, como a literatura mostra sobejamente, as estruturas neuronais constante e caracteristicamente lesadas na doença de Alzheimer são as do núcleo de Meynert que se situa exclusivamente em nível sub-cortical as da formação hipocampal que inclue estruturas corticais e sub-corticais e as do Locus Cöeruleus, no tronco cerebral. Na doença de Parkinson, a síndrome demencial aparece nos estádios mais tardios da doença, quando as lesões verificadas são superponíveis às da doença de Alzheimer. Vale acrescentar que transtornos afásicos têm sido evidenciados em estádios relativamente precoces, na doença de Parkinson. Por estas razões não admitimos a existência dos tipos cortical e sub-cortical de demência.

\section{O DIAGNÓSTICO ETIOLÓGICO DA DEMENCIA}

O definitivo diagnóstico etiológico da demência só tem sido possível pelo exame histológico do tecido nervoso, em amostras colhidas nas estruturas que são reconhecidamente comprometidas na patogenia desta síndrome. O exame histologico deve obedecer normas atualmente já amplamente reconhecidas, capazes de estabelecer com segurança o diagnóstico. A pesquisa da etiologia, entretanto, deve ser iniciada na fase clínica e em uma primeira etapa se destina a demonstrar processos patológicos evidenciáveis aos testes bioquímicos (Cisticercose, Lues, Aids, hipotireoidismo, deficiência em Vitamina $\mathrm{B} 12$, insuficiência renal -especialmente em pacientes em tratamento por diálise, insuficiência hepática), exames de neuro-imagem (neoplasias cerebrais, hematomas intracranianos, hidrocefalias, cisticercose, lues), causas pouco frequentes mas não excepcionais de demência.

\section{COMENTÁRIOS FINAIS}

A realização das etapas acima relacionadas com utilização apropriada e cuidadosa de todas as técnicas aqui enumeradas confere, para o diagnóstico etiológico, segurança entre $80 \%$ e $100 \%$, estando entre estas etiologias, as doenças causadoras de atrofia primária do parênquima nervoso, as doenças inflamatórias e infecciosas, as coleções sanguíneas intra e extraparenquimatosas cerebrais, as neoplasias intracranianas. É de consenso universal considerar-se demência verdadeira a demência que tem como etiologia a degeneração primária do parênquima encefálico. É com relativa facilidade que se pode realizar o diagnóstico etiológico in vivo, nos casos em que a demência é causada por agentes diferentes da degeneração primária do tecido nervoso, utilizando os atuais subsídios laboratoriais disponíveis. Por esta razão tem sido muito grande o esforço, nos Serviços que se dedicam ao estudo das demências, destinado a desenvolver e aperfeiçoar métodos e técnicas para o diagnóstico da demência verdadeira. Esse esforço tem sido muito proveitoso e a segurança do diagnóstico já atinge cerca de $90 \%$ em recentes casuísticas.

\section{SUMMARY}

The present paper provides a brief history of the development of the concept of Infantile Austism since its first description by Leo Kanner in 1943 until nowadays. It also analises the new trends in diagnosti criterias and classifications of the Autistic Syndrome in both ICD 10 and DSM IV. ts

\section{KEY WORDS}

Dementia. Diagnostic. 